\title{
Perencanaan Sistem Plambing Air Bersih dan Air Buangan di Rusunami X dengan Aspek Konservasi Air
}

\author{
Amda Rahman ${ }^{1 *}$, Eka Wardhani ${ }^{2}$, Nico Halomoan ${ }^{3}$ \\ 1,2,3 Teknik Lingkungan, Institut Teknologi Nasional, Bandung \\ *Koresponden email: amda.rahman87@gmail.com, ekawardhani08@gmail.com
}

Diterima: 26 Februari 2021

Disetujui: 21 Juni 2021

\begin{abstract}
Flat X will be built to meet the demand for simple and affordable homes in Sumedang Regency. The construction of an apartment must be equipped with adequate plumbing for clean water and wastewater so that the health of the residents is maintained. The purpose of this research is to plan the need for clean water, including the calculate dimensions of the groundwater reservoir, roof reservoir, and clean water pipe and calculate wastewater discharges ( grey and black water) and calculate the use of greywater recycling. Recycled water is used in the rinsing and watering of plants. Research results for a flat population that can reach 3,658 people, the total requirement for clean water which is $311 \mathrm{~m}^{3} /$ day, the volume of underground reservoir 1 and 2 each $352 \mathrm{~m}^{3}$ and $165 \mathrm{~m}^{3}$. The volume of roof reservoir 1 and 2 is $42 \mathrm{~m}^{3}$ and $34 \mathrm{~m}^{3}$, respectively. The diameter of the $\mathrm{r}$ first class clean water pipe has a range of 20-25 $\mathrm{mm}$, the diameter of the second class clean water pipe has a range of $25-25 \mathrm{~mm}$, pipe diameter greywater has a range from $48-60 \mathrm{~mm}$, pipe diameter black water range $48-114 \mathrm{~mm}$. Greywater treatment is carried out using a Sewage Treatment Plant (STP) which has a volume of $200 \mathrm{~m}^{3}$. The results of the treatment efficiency are $80 \%$, so the recycling process is capable of saving $51 \%$ of clean water.
\end{abstract}

Keywords: water conservation, wastewater, water-saving, plumbing, apartment

\begin{abstract}
Abstrak
Rusunami X akan dibangun untuk memenuhi kebutuhan rumah sederhana dan terjangkau masyarakat di Kabupaten Sumedang. Pembangunan Rusunami harus dilengkapi dengan fasilitas plambing air bersih dan air buangan yang memadai supaya kesehatan penghuni terjaga. Tujuan dari penelitian ini adalah merencanakan kebutuhan air bersih, meliputi perhitungan ground water tank, roof tank dan dimensi pipa air bersih, merencanakan dan menghitung debit air limbah (grey water dan black water) dan menghitung pemanfaatan daur ulang grey water. Air hasil daur ulang dipergunakan untuk penggelontoran dan penyiraman tanaman. Hasil penelitian untuk populasi Rusunami sebanyak 3.658 jiwa, kebutuhan total air bersih yaitu $311 \mathrm{~m}^{3} /$ hari, volume ground tank 1 dan 2 masing-masing $352 \mathrm{~m}^{3}$ dan $165 \mathrm{~m}^{3}$. Volume roof tank 1 dan 2 masing-masing $42 \mathrm{~m}^{3}$ dan $34 \mathrm{~m}^{3}$. Diameter pipa air bersih first class mempunyai rentang 20$25 \mathrm{~mm}$, diameter pipa air bersih second class mempunyai rentang 25-25 mm, Diameter pipa grey water mempunyai rentang 48-60 mm, diameter pipa black water rentang 48-114 mm. Pengolahan grey water dilakukan menggunakan Sewage Treatment Plant (STP) yang mempunyai volume $200 \mathrm{~m}^{3}$. Hasil efisiensi pengolahan $80 \%$, sehingga dengan proses daur ulang itu mampu menghemat air bersih sebesar $51 \%$.
\end{abstract}

Kata Kunci: konservasi air, air limbah, penghematan air, plambing, rusunami

\section{Pendahuluan}

Bangunan hijau merupakan konsep untuk mengembangkan bangunan yang ramah lingkungan, hemat energi, hemat air, serta meminimalkan penggunaan sumber daya alam yang ada dengan tetap mempertahankan fungsi dari bangunan tersebut. Penerapan bangunan hijau mampu dapat mengurangi dampak bangunan baru terhadap lingkungan dan kesehatan manusia [1]. Konsep ini memiliki banyak yang salah satunya adalah konservasi air. Konservasi air bertujuan mengurangi penggunaan air bersih untuk keperluan sehari-hari dan mengurangi timbulan air limbah yang dihasilkan [1]. Aspek yang dikaji dalam konservasi air antara lain penggunaan meteran air untuk mengetahui jumlah pemakaian, perhitungan penggunaan air, pengurangan penggunaan air, penggunaan alat-alat plumbing/fitur air yang mampu menghemat penggunaan air, proses mendaur ulang air, pemanfaatan sumber air alternatif seperti air bekas (grey water) air bekas wudhu, penampungan air, dan efisiensi penggunaan air lansekap [1]. Konsep bangunan hijau harus mulai digalakkan mengingat semakin langkanya ketersediaan air bersih di berbagai daerah di Indonesia sehingga semua kalangan harus mulai menerapkan konsep penghematan air untuk semua keperluan baik domestik, non domestik, industri, dan pertanian. 
Rumah susun sederhana milik (Rusunami) merupakan fasilitas pemukiman yang disediakan oleh pemerintah untuk memenuhi kebutuhan papan masyarakat ekonomi menengah ke bawah. Rusunami tetap harus dilengkapi dengan fasilitas sanitasi yang baik guna memberikan kenyamanan dan menjamin kesehatan pengguna. Fasilitas utama Rusunami yang harus tersedia yaitu sistem pelayanan air bersih yang memenuhi tiga syarat yaitu kualitas, kuantitas, dan kontinuitas [2]. Penerapan konsep bangunan hijau terutama aspek konservasi air harus mulai diterapkan supaya penggunaan air optimal. Rusunami X akan dibangun di Kabupaten Sumedang Provinsi Jawa Barat dengan tujuan menyediakan perumahan murah bagi warga kabupaten Sumedang dan sekitarnya. Rusunami X yang direncanakan memiliki 15 lantai yang dibangun pada lahan seluas 6.059 dengan total jumlah unit yang disediakan sebanyak 756 unit [3].

Penelitian mengenai konservasi air telah banyak dilakukan seperti di Rumah Sakit Universitas Sam Ratulangi yang memiliki jumlah populasi sebanyak 2.962 orang sehingga diperlukan air bersih sebesar $372,48 \mathrm{~m}^{3} /$ hari. Penelitian tersebut membandingkan pemakaian air dengan alat plambing konvensional dengan yang hemat air dimana disimpulkan bahwa pemakaian air menggunakan alat plambing nonkonvensional lebih kecil dibandingkan standar alat plambing konvensional dimana persentase penghematan mencapai 40,64\% [5]. Penelitian lain dengan melakukan pengolahan air limbah domestik (grey water) yang dilakukan di Inkubator Bisnis (INBIS) Permata Bunda di Kampung Aren Kota Bontang Kalimantan Timur menyimpulkan bahwa pengolahan air mampu reduksi parameter pencemar antara 56,73-97,65\% dan air hasil olahan dapat dimanfaatkan kembali mengingat telah memenuhi baku mutu untuk parameter, $\mathrm{pH}$, BOD, COD, Amoniak, Minyak Lemak dan Total Coliform, namun untuk parameter TSS dan Total Coliform perlu evaluasi operasional [6]. Penelitian lain yaitu perencanaan sistem instalasi plambing air bersih, menggunakan aspek konservasi air dengan cara daur ulang air limbah dan pemanenan air hujan di Apartemen Cibinong Menara Matoa Tower E yang mampu menghemat air bersih sebesar 33\% atau sekitar $305,88 \mathrm{~m}^{3} /$ hari [7]. Penelitian pengukuran kuantitas air buangan pada fasilitas yang ada di Kampus Universitas Andalas dimana menghasilkan data total air buangan Kampus Unand Limau Manis adalah sebesar 1.439,6 $\mathrm{m}^{3} /$ hari, dengan komposisi air buangan yaitu, air bekas $812,3 \mathrm{~m}^{3} /$ hari $(52,67 \%)$, air buangan khusus $343,8 \mathrm{~m}^{3} /$ hari $(23,45 \%)$ dan air kotor $337,5 \mathrm{~m}^{3} /$ hari $(23,88 \%)$, dimana komposisi tersebut dapat dijadikan data dasar untuk menentukan jumlah air limbah yang dapat di daur ulang [8]. Potensi penghematan air melalui pemanfaatan kembali air bekas untuk kebutuhan flushing WC dan urinal serta pemasangan meter air di Gedung Panghegar Resort Dago Golf-Hotel and spa mampu menghemat air sebesar 25\% [9]. Hasil penelitian yang telah dilakukan mampu menjawab pertanyaan potensi jumlah air yang dapat di hemat dengan penerapan aspek konservasi air.

Maksud dari penelitian ini adalah merencanakan sistem plambing air bersih dan air buangan di Rusunami X dilihat dari persyaratan peruntukan bangunan gedung seperti yang tertuang dalam Peraturan Daerah Kabupaten Sumedang Nomor 15 Tahun 2011 tentang bangunan gedung. Peraturan tersebut menyatakan bahwa semua bangunan yang akan di bangun di Kabupaten Sumedang harus menerapkan konsep bangunan hijau diantaranya penghematan air mengingat kondisi sumber air baku yang semakin langka [4]. Tujuan dari penelitian ini merencanakan dan menghitung debit air bersih, air limbah (grey water) dan menghitung persentase pemanfaatan air daur ulang tersebut.

\section{Metode Penelitian}

Penelitian dimulai dengan melakukan studi literatur mengenai teori, standar, dan peraturan yang berhubungan dengan perencanaan sistem plambing. Hasil studi Pustaka berguna dalam menganalisis hasil penelitian yang telah dilakukan. Penelitian terdiri dari empat tahap yaitu perhitungan kebutuhan air, timbulan air limbah domestik, instalasi hemat air, dan proses daur ulang air. Tahap pengolahan data terdiri dari perhitungan populasi gedung untuk mengetahui kebutuhan air bersih, pertama mencari luas efektif dengan cara mengkalikan luas area dengan \% luas efektif [10] [11]. Jumlah populasi dilakukan dengan membagi luas efektif yang telah diperoleh dengan standar populasi. Kebutuhan air bersih digunakan untuk menghitung timbulan air limbah, diperoleh dengan cara mengkalikan jumlah populasi yang sudah didapatkan dari perhitungan sebelumnya dengan standar kebutuhan air 10] [11]. Mencari debit air limbah dilakukan untuk mendapatkan timbulan grey water yang akan didaur ulang. Berdasarkan Permen-PUPR Nomor 4 Tahun 2017 rasio air limbah yang dihasilkan dalam satu gedung sebesar $80 \%$ dari total kebutuhan air bersih. Rasio grey water sebesar $80 \%$ dari total debit air limbah [12] [13]. Persamaan untuk menentukan luas efektif, populasi, kebutuhan air bersih dan timbulan grey water disajikan pada persamaan 1-6. 
Populasi $=\frac{\text { Luas efektif } \mathrm{m}^{2}}{\text { Standar Populasi } \mathrm{m}^{2} / \text { orang }}$

Kebutuhan Air Bersih = Jumlah populasi $\mathrm{x}$ Standar pemakaian air bersih = (1/orang/hari)

$\mathrm{Q}_{\text {air limbah }}=80 \% \mathrm{x}$ Jumlah total kebutuhan air bersih $=\left(\mathrm{m}^{3} /\right.$ hari $)$

$\mathrm{Q}_{\text {greywater }}=Q$ air limbah $\times 80 \%=\left(\mathrm{m}^{3} / \mathrm{hari}\right)$

Grey water dapat didaur ulang dengan menggunakan STP (Sewage Treatment Plant). Perencanaan STP terdiri dari penentuan kapasitas pengolahan, jenis unit pengolahan, serta menghitung efisiensi yang didapatkan dengan rumus disajikan pada persamaan 6.

$$
\text { Efisiensi }=\frac{\text { Total air daur ulang }}{\text { Total kebutuhan air daur ulang }} x 100 \%
$$

\section{Hasil dan Pembahasan}

Pembangunan Rusunami X direncanakan memiliki dua tower dengan jumlah masing-masing sebanyak 15 lantai dan 378 unit sehingga total akan tersedia 756 unit kamar. Rusunami X dibangun pada lahan seluas 6.059,00, dimana tower A dan B akan dilengkapi dengan fasilitas penunjang seperti area parkir, Ruang Terbuka Hijau (RTH), saluran limbah, aliran listrik, alat komunikasi, fasilitas peribadatan, dan lapangan olah raga [3]. Rencana ruangan Rusunami X tipe A direncanakan dibangun dengan ukuran 3,0 x 5,0 meter yang difasilitasi dengan toilet, ruang tidur, balkon dan rencana ruangan Rusunami X tipe B direncanakan dibangun dengan ukuran 5,8 x 4,5 meter dengan fasilitas seperti toilet, ruang tidur, ruang makan, ruang duduk dan balkon [3]. Ruangan kamar tipe A disajikan pada Gambar 1 dan kamar tipe B disajikan pada Gambar 2.

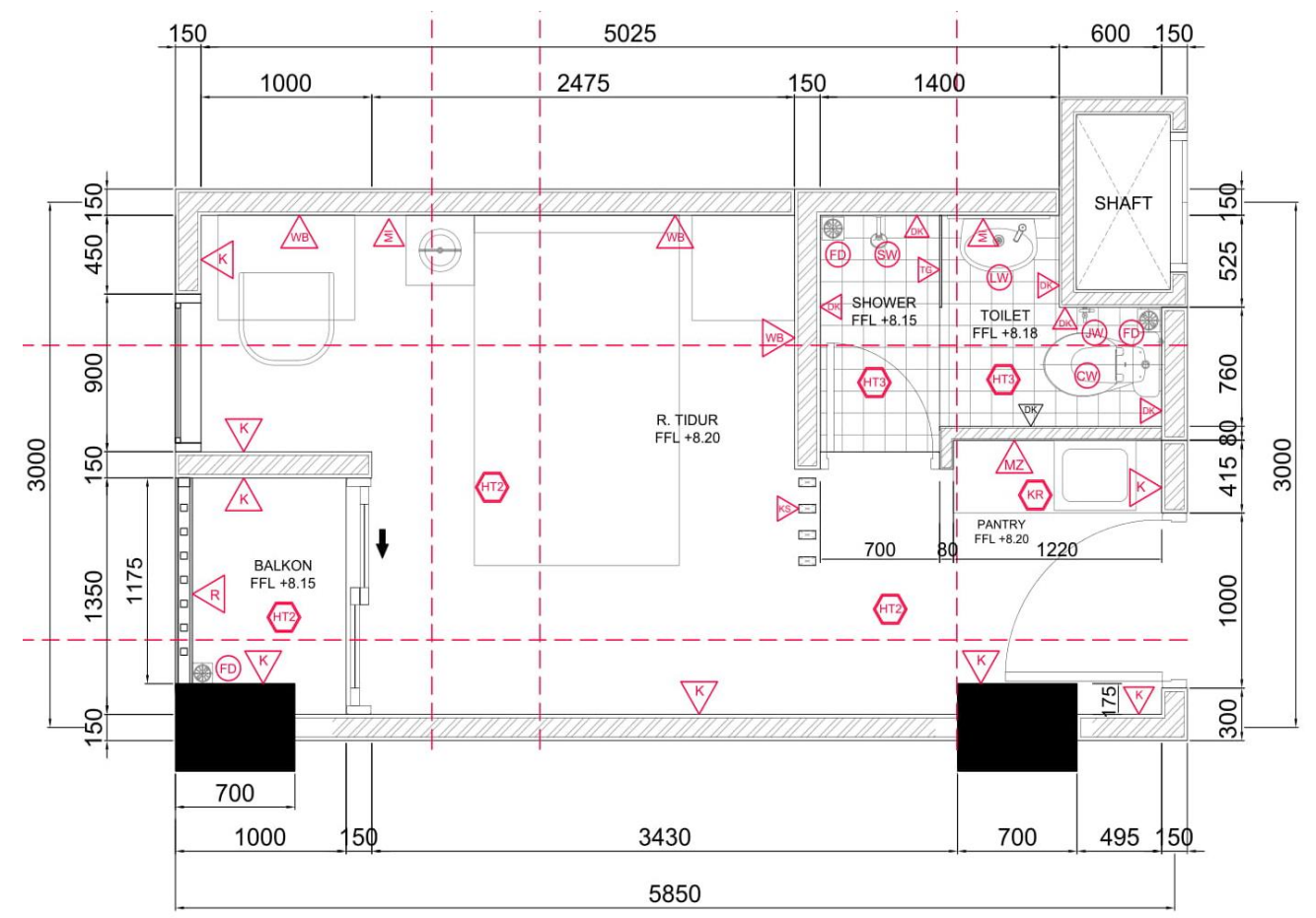

Gambar 1. Ruangan kamar tipe A Sumber: [3] 


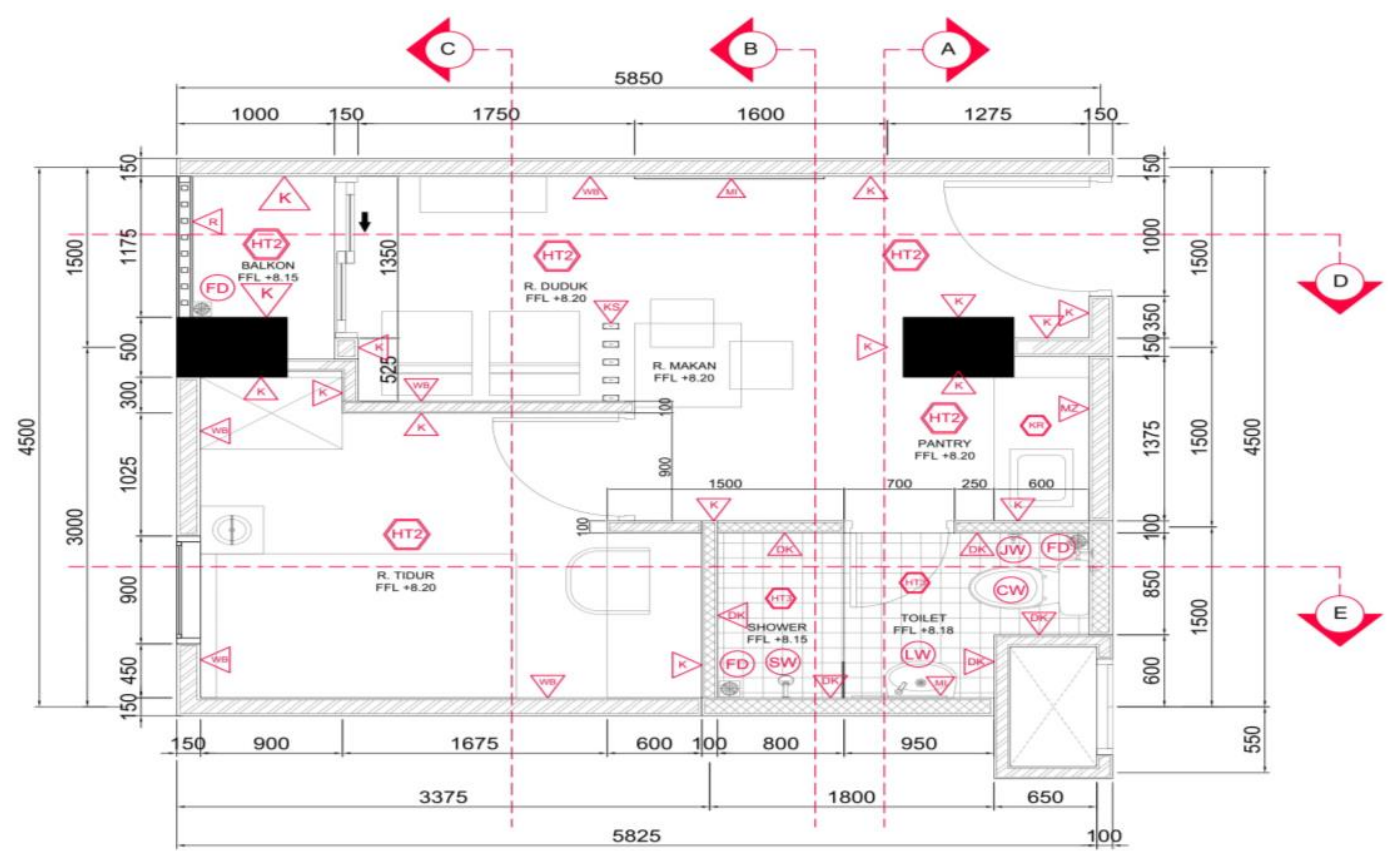

Gambar 2. Ruangan kamar tipe B

Sumber: [3]

Sumber air bersih untuk memenuhi kebutuhan aktivitas domestik di Rusunami X seperti mandi, mencuci, memasak dan lainnya berasal dari PDAM Tirta Medal. Pihak PDAM telah menyanggupi untuk memasok air sesuai permintaan pengelola Rusunami X [3]. Kebutuhan air bersih di Rusunami X sebesar $311 \mathrm{~m}^{3} /$ hari seperti ditampilkan pada Tabel 2. Berdasarkan tabel tersebut terdapat angka safety factor sebesar 20\% dari debit total yang diperhitungkan untuk mengantisipasi lonjakan air saat terjadi pemakaian puncak. Perhitungan jumlah penghuni dengan mempertimbangkan jumlah kamar sebanyak 756 unit mampu menampung 3 orang. Jumlah karyawan sebanyak 12 orang berasal dari data pihak pengelola sedangkan jumlah pengunjung diprakirakan dari sebesar $70 \%$ dari jumlah penghuni. Pengunjung merupakan tamu, asisten rumah tangga, pengantar makanan serta orang yang bersangkutan dengan penghuni Rusunami [3]

Tabel 2. Rekapitulasi air bersih

\begin{tabular}{lcccc}
\hline \multicolumn{1}{c}{ Jenis } & Jumlah orang & Kebutuhan air & \multicolumn{2}{c}{ Debit Total } \\
\hline & (Jiwa) & $1 / \mathrm{o} / \mathrm{h}$ & $1 /$ hari & $\mathrm{m}^{3} /$ hari \\
\hline Penghuni & 2.128 & 100 & 212.800 & 212,8 \\
Karyawan & 12 & 50 & 600 & 0,6 \\
Pengunjung & 1.518 & 30 & 45.540 & 45,54 \\
\hline total & & 258.940 & 258,94 \\
\hline Safety Factor & $(20 \%)$ & 51.788 & 51,79 \\
\hline \multicolumn{2}{c}{ Total kebutuhan air bersih Rusunami X $\left(\mathrm{m}^{3} / \mathrm{hari}\right)$} & 310.728 & 311,00 \\
\hline
\end{tabular}

Sumber: Perhitungan, 2021.

Penentuan jalur pipa bersih berdasarkan denah perencanaan pembangunan Rusunami dari setiap lantainya sedangkan untuk perhitungan dimensi pipa air bersih ditentukan menggunakan unit beban alat plambing [10]. Berdasarkan hasil analisis perencanaan jalur air bersih di Rusunami X akan direncanakan 2 jalur, yaitu jalur air bersih first class dengan rentang diameter pasaran 20-25 $\mathrm{mm}$ dan second class dengan diameter berkisar antara 20-25 mm. Skematik pelayanan air bersih di Rusunami X disajikan pada Gambar 3. Berdasarkan gambar tersebut air dari PDAM Tirta Medal ditampung di ground water tank sebelum di pompa ke roof tank, dari roof tank dialirkan secara gravitasi ke seluruh alat plambing yang ada seluruh kamar [3]. Sistem pompa bekerja membuat perbedaan tekanan antara tekan masuk (suction) dan bagian keluar (discharger) yang mengubah tenaga mekanik dari tenaga (penggerak) menjadi tenaga kinetic (kecepatan) pada pompa, sehingga air dapat mengalir dan tidak terjadi kekurangan tekan [14], [15]. Pompa secara umum yang digunakan untuk rumah susun, hotel dan apartemen ada dua jenis yaitu: (1) pompa transfer adalah pompa yang umumnya dipasang pada ground tank, yang dimana ground tank ini adalah tempat sumber utama air sebelum dialirkan ke masing-masing ruangan. Pompa transfer bekerja untuk mengirimkan air dari ground tank menuju pada roof tank dan (2) pompa booster adalah pompa yang 
menyalurkan air dari roof tank ke masing-masing alat plambing. Fungsi utamanya adalah untuk memenuhi distribusi air pada lokasi dengan jarak atau ketinggian tertentu [14], [15]. Konsep yang sama diterapkan untuk sistem penyediaan air bersih di Rusunami X seperti disajikan pada Gambar 3. Penggunaan pompa booster di pergunakan untuk melayani air bersih di lantai 12 sampai dengan 15 seperti disajikan pada Gambar 4. Sistem tekan menggunakan pompa booster digunakan untuk mendistribusi pada lantai 12 sampai lantai 15, dikarenakan untuk alat plambing shower memiliki tekanan sebesar 0,7 bar [14], [15].

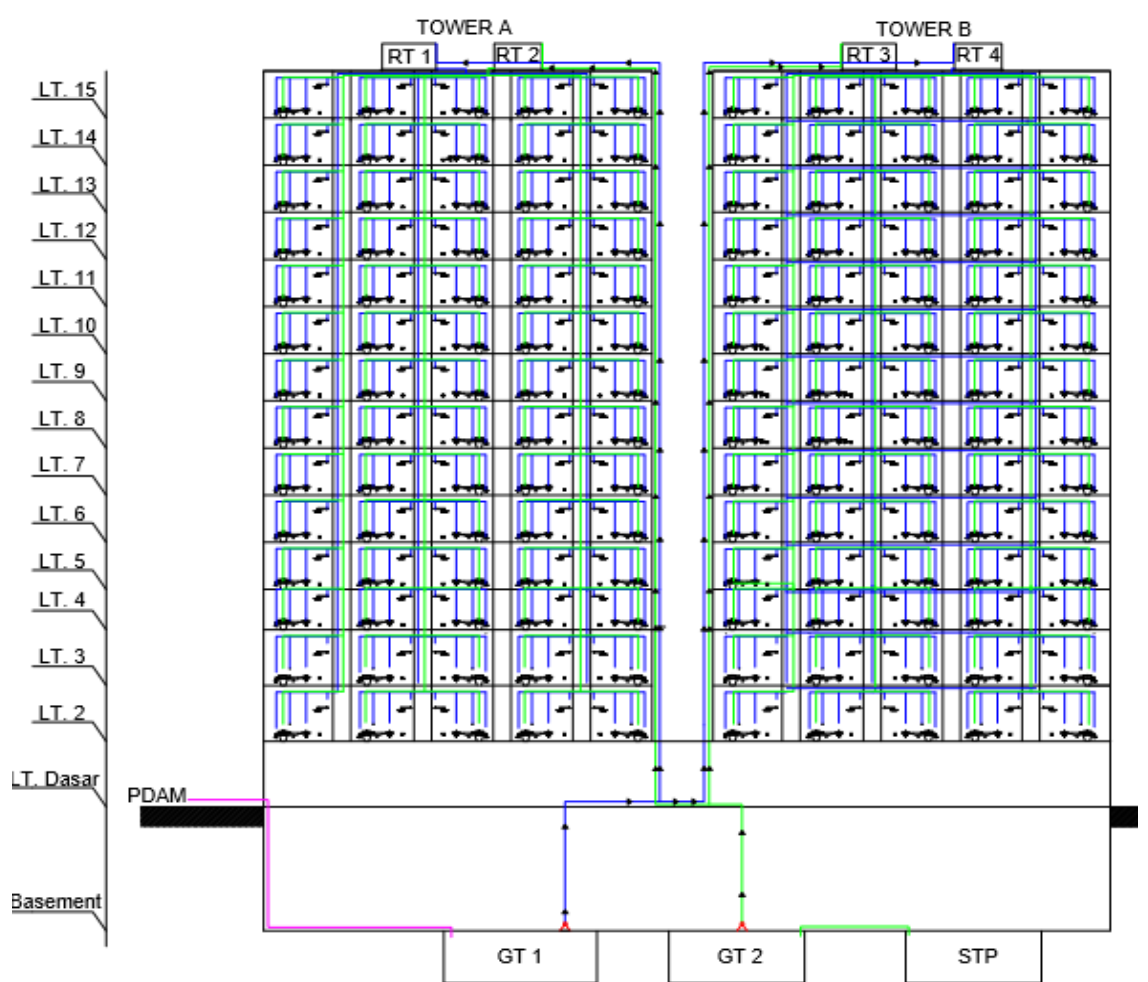

Gambar 3. Skema sistem penyediaan air bersih di Rusunami X Sumber: [3]

Keterangan:

:Pipa PDAM, GT1: Ground tank 1

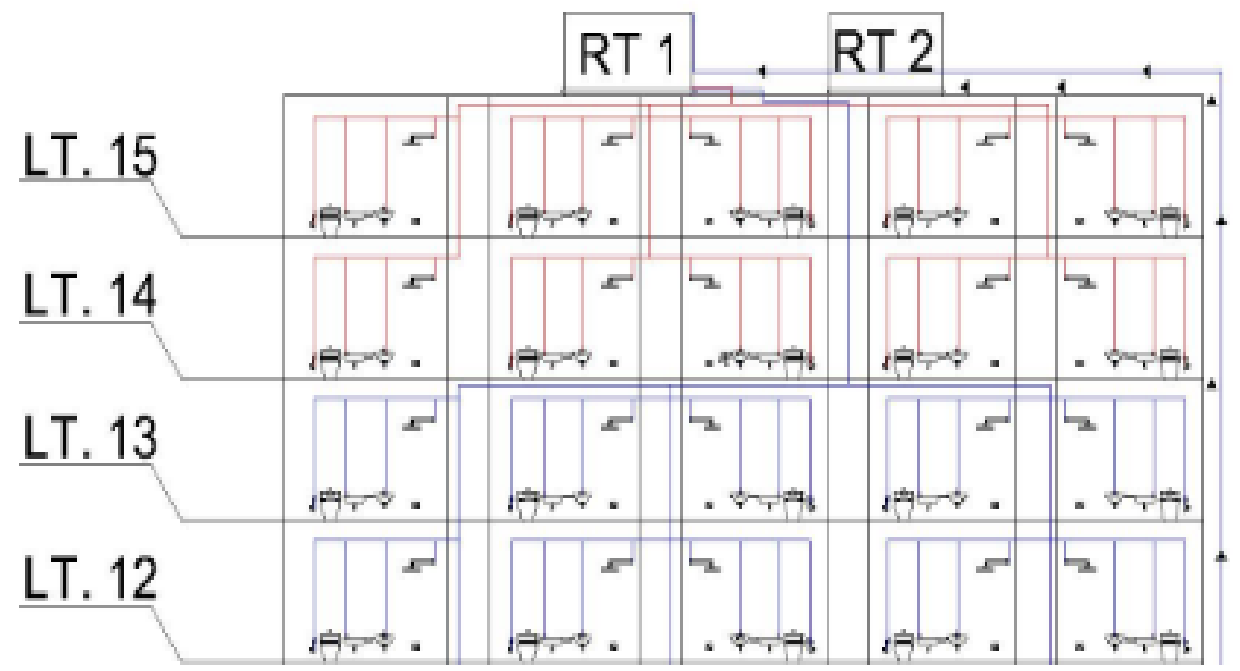

Gambar 4. Penempatan Pompa Booster di Rusunami X

Sumber: [3]

Keterangan:

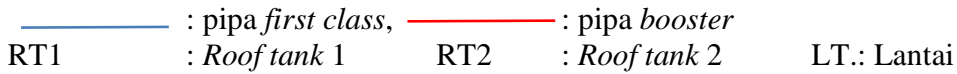


Menentukan jalur pipa air buangan berdasarkan alat plambing yang digunakan pada Rusunami X, penentuan diameter pipa air buangan berdasarkan unit beban plambing [10]. Perencanaan jalur air buangan di Rusunami $\mathrm{X}$ akan direncanakan 2 jalur, yaitu jalur air buangan grey water dengan diameter berkisar antara 48-60 mm dan black water dengan diameter maksimal $144 \mathrm{~mm}$. Sistem penyaluran air buangan terutama black water dilengkapi dengan vent untuk mengeluarkan bau yang timbul dari air buangan. Penentuan jalur pipa vent berdasarkan pipa air black water yang digunakan pada Rusunami X, dan diameter pipa vent berdasarkan unit beban alat plambing. Berdasarkan hasil perencanaan jalur pipa vent di Rusunami $\mathrm{X}$ akan direncanakan yaitu dengan rentang diameter antara 48-76 mm. Perencanaan vent yang baik akan menghindari bau yang muncul di pipa air limbah karena terjadi sirkulasi oksigen yang baik.

Debit air buangan di Rusunami X untuk grey water 199,04 $\mathrm{m}^{3} /$ hari dan black water $49,76 \mathrm{~m}^{3} / \mathrm{hari}$. Air limbah grey water akan diolah Kembali sehingga memenuhi syarat untuk keperluan flushing alat plambing WC agar mengurangi pemakaian air dari sumber utama. Air limbah tersebut diolah menggunakan STP dengan volume $200 \mathrm{~m}^{3}$. Air limbah black water akan ditampung di dalam tanki septik dengan volume $60 \mathrm{~m}^{3}$ yang dilengkapi dengan bidang resapan. Lumpur dari tangki septik secara periodik akan disedot dan diambil oleh pihak ketiga berizin untuk diolah di instalasi pengolahan lumpur tinja (IPLT) yang terdapat di Kabupaten Sumedang.

STP adalah sistem pengolahan air limbah domestik yang menggunakan prinsip pengolahan biologi. Proses anaerob dan aerob dipergunakan untuk mengolah air limbah grey water sehingga kandungan organik yang terkandung di dalamnya akan tersisihkan [16]. Target pengolahan air yaitu parameter-parameter dengan besaran yang tertuang dalam PPLH No 68/Tahun 2016 tentang Baku Mutu Air Limbah Domestik [17]. Parameter tersebut yaitu $\mathrm{pH}, \mathrm{BOD}_{5}, \mathrm{COD}$, TSS, minyak dan lemak, amoniak, dan total Coliform. STP dilengkapi dengan pengolahan primer yang terdiri dari unit saringan/screen dan tangki ekualisasi. Fungsi pengolahan primer yaitu mempersiapkan air limbah supaya siap diolah di unit biologi. Parameter yang disisihkan yaitu sampah, pasir, dan partikel diskrit. Tahap ini juga berfungsi untuk menyeragamkan konsentrasi dan debit sehingga air yang masuk ke proses biologi masuk secara merata. Tahap akhir dilakukan proses pengolahan kimiawi dengan menggunakan klorin untuk menyisihkan bakteri Coliform yang terkandung dalam air limbah. Penjelasan detail mengenai masing-masing unit pengolahan disajikan pada uraian berikut.

1. Pengolahan Primer, terdiri dari grease trap dan screen yang berfungsi untuk memisahkan air limbah dari lemak, minyak dan sampah padat. Tangki ekualisasi, berfungsi untuk meratakan beban bahan organik dan debit air limbah. Tangki ini dilengkapi dengan pengaduk dan alat ukur debit sehingga air hujan siap untuk dialirkan ke tahap selanjutnya.

2. Pengolahan sekunder terdiri dati proses biologi anaerob dan anerob. Tahap Anaerobik, pada tangki ini penguraian partikel organik oleh mikroorganisme tanpa menggunakan oksigen. Tahap Aerobik, pada tangki ini akan terjadi penguraian partikel organik oleh mikroorganisme pengurai secara aerob dengan bantuan mesin blower. Hasil akhir dari proses pengolahan biologi masuk ke tangki sedimentasi, lumpur atau biomassa yang lolos akan mengendap di dasar tangki sedimentasi. Pada tangki ini akan terjadi proses pemisahan lumpur dengan air limbah. Lumpur biologis yang dihasilkan akan diolah di unit pengolahan lumpur.

3. Pengolahan tersier dilakukan proses klorinasi, pada bak klorinasi ini air limbah direaksikan dengan senyawa klor untuk membunuh mikroorganisme patogen yang ada dalam air limbah sehingga air aman untuk dipergunakan untuk flushing alat plambing.

Proses daur ulang air limbah yang dilakukan dapat mengurangi kebutuhan air bersih sebesar $51 \%$ atau $159,2 \mathrm{~m}^{3} /$ hari. Selain menghemat penggunaan air proses ini juga turut menjaga kelestarian lingkungan mengingat saat ini sumber air baku di Kabupaten Sumedang semakin langka. Selain proses daur ulang air perlu dilakukan pula upaya kampanye hemat air untuk seluruh penghuni Rusunami. Poster dan papan pengumuman di pasang di semua tempat sumber air sehingga timbul kesadaran penghuni untuk turut menghemat penggunaan air.

\section{Kesimpulan}

Berdasarkan hasil perencanaan dan perhitungan, maka kesimpulan yang didapat adalah timbulan air limbah Rusunami X sebesar 248,8 $\mathrm{m}^{3} /$ hari terdiri dari grey water sebesar 199,04 $\mathrm{m}^{3} / \mathrm{hari}$ dan black water sebesar 49,76 $\mathrm{m}^{3} / \mathrm{hari}$. Air limbah grey water didaur ulang menggunakan STP dan black water direncanakan menggunakan tangki septik dengan bidang resapan. Lumpur tinja dari tangki septik akan disedot oleh pihak ketiga berizin. Debit air limbah grey water yang didaur ulang mampu menghemat penggunaan air sebesar $51 \%$. Air hasil daur ulang tersebut akan dipergunakan untuk penggelontoran WC. Kampanye penghematan 
air bagi semua penghuni harus dilakukan untuk mendukung proses daur ulang yang terjadi. Hasil akhir yang diperoleh diharapkan terjadinya pengurangan pemakaian air baku di Kabupaten Sumedang.

\section{Referensi}

1. . 2013. Penilaian Bangunan Hijau Untuk Bangunan Baru Versi.2 Green Building Council Indonesia.

2. Puti Sri Komala, Suarni S. Abuzar, Purnama Mentari Dewi. 2019. Perencanaan Sistem Plambing Air Buangan Gedung Rusunawa Mahasiswa Universitas Andalas. Serambi Engineering Volume IV Edisi Khusus Oktober 2019 583-592

3. - 2020. Detail Engineering Design Rusunawa X Kabupaten Sumedang. Provinsi Jawa Barat

4. Peraturan Daerah Kabupaten Sumedang Nomor 15 Tahun 2011 Tentang Bangunan Gedung di Kabupaten Sumedang Provinsi Jawa Barat

5. Adeyra Khairunisa Rahayu, Yulianti Pratama, Anindito Nurprabowo. (2020). Perencanaan Sistem Instalasi Plambing Air Bersih dengan Penerapan Alat Plambing Hemat Air Di Rumah Sakit Universitas Sam Ratulangi Serambi Engineering Volume 5 No 2 April tahun 2020

6. Muhammad Busyairi, Nikita Adriyanti, Abdul Kahar, Dian Nurcahya, Sariyadi, Tathok D Hudayana. 2020. Efektivitas Pengolahan Air Limbah Domestik Grey Water Dengan Proses Biofilter Anaerob dan Biofilter Aerob (Studi Kasus: IPAL INBIS Permata Bunda, Bontang) Serambi Engineering, Volume V, No. 4, Oktober 2020 hal 1306-1312

7. Wahyudi dan Eka Wardhani. (2019). The Use of Plumbing Tools Saving Water with Efforts to Save Clean Water with Application of Green Building Concept at Menara Cibinong Apartment. Journal of Architectural Research and Education Vol 1(No.2), 2019

8. Puti Sri Komala, Yenni Ruslinda, Juwita Zurienra. 2020. Studi Kuantitas Air Buangan Kampus Universitas Andalas Limau Manis Padang, Serambi Engineering, Volume V, No. 2, April 2020 hal 1050-1062

9. Dhea Yafina Rinka, M. Rangga Sururi, Eka Wardhani. 2014. Perencanaan Sistem Plambing Air Limbah dengan Penerapan Konsep Green Building pada Gedung Panghegar Resort Dago Golf-Hotel\&Spa. Jurnal Reka Lingkungan Vol 2, No 2 (2014)

10. . 2005. "Tata Cara Perencanaan Sistem Plambing." Standar Nasional Indonesia (SNI)-03-70652005.

11. . 2015. Badan Standarisasi Nasional. (2015). Sistem Plambing pada bangunan gedung (SNI 8153 2015)," Badan Standarisasi Nasional Indonesia

12. Cahyadi, V. L. (2012). Perencanaan Bangunan Instalasi Universitas Indonesia Manajemen Lingkungan

13. Hardjosuprapto, M. M. (2000). Penyaluran Air Buangan. Bandung: Institut Teknologi Bandung.

14. Mahmudi, Ali. 2015. Pompa Dan Kompresor Buku Bahan Ajaran Jurusan Teknik Mesin Politeknik Negeri Bandung

15. Sularso, H. T. 1987. Pompa dan Kompresor Pemilihan, Pemakaian dan Pemeliharaan P.T Prandnya Paramita.

16. Gita Ayu Rahmawati, Eka Wardhani, Lina Apriyanti. 2019. Perencanaan Instalasi Pengolahan Air Limbah Mal X Kota Bandung Serambi Engineering, Volume IV, No.2, Juli 2019 hal 522-531

17. Kementerian Lingkungan Hidup dan Kehutanan Republik Indonesia. 2016. Peraturan Menteri Lingkungan Hidup 68 Tahun 2016 tentang Baku Mutu Air Limbah Domestik. 